\title{
Forma e substância na linguagem: reflexões sobre o bilinguismo do surdo
}

\author{
Núbia Rabelo Bakker Faria \\ Doutora em Letras, Professora do Programa \\ de Pós-Graduação em Letras e Linguística da \\ Faculdade de Letras da Universidade Federal de \\ Alagoas.
}

Resumo: A partir das reflexões de Hjelmslev (1943) sobre forma e substância da linguagem, este artigo discute, no âmbito da educação do surdo, o conceito de bilinguismo, que assume ser a Libras a primeira língua e o português, na modalidade escrita, a segunda língua. É dado destaque as características formais da linguagem, condição para que se possam considerar as possibilidades de o surdo ter acesso a uma língua oral de escrita alfabética unicamente através da sua materialidade gráfica. As implicações do conceito de língua natural e o lugar secundário atribuído à escrita serão igualmente discutidos a partir de De Lemos $(1992,2002)$ e Derrida (1973), respectivamente.

Palavras-chave: bilingüismo; surdo; forma; substância
Abstract: Based on Hjelmslev's (1943) reflexions on form and substance of language, this article discusses the concept of bilingualism, in the context of the education of deaf, advocating Libras as the first language and Portuguese, in the written form, as the second language. It shall be given emphasis on the formal characteristics of language, as a means of addressing the possibilities of the deaf reach an oral language with alphabetic writing system solely through its written materiality. The implications of the concept of natural language and the role of writing as a secondary mode of language will be discussed as well, based on De Lemos $(1992,2002)$ and Derrida (1973), respectively.

Key-words: bilingualism; deaf; form; substance 



\section{Introdução}

A educação do surdo tem sido tema de uma série de pesquisas e discussões recentes no Brasil (e.g. QUADROS, 1997; KARNOPP, 1994; SKLIAR, 1998; FERNANDES, 2003). Segundo Quadros (2003), a Língua Brasileira de Sinais (Libras) começou a ser investigada na década de 80 e a aquisição desta, nos anos 1990 . Será, entretanto, a partir de 2002, com a lei 10.436, que reconhece a Libras como meio legal de comunicação e expressão, e o decreto 5.626 de 2005, que determina a inclusão da Língua Brasileira de Sinais como disciplina curricular, que observaremos uma grande produção acadêmica com essa temática. São estudos e análises relativos, por exemplo, à constituição da identidade da comunidade surda, às características linguísticas da Libras, à inclusão dos surdos nas escolas regulares, às práticas pedagógicas implicadas nessa inclusão, ao enfrentamento do discurso clínico-terapêutico responsável pela percepção do surdo como "deficiente de linguagem" e, de modo particular, ao ensino do português escrito ao surdo, uma vez que a lei 10.436, supra mencionada, destaca que "a Libras não poderá substituir a modalidade escrita da língua portuguesa".

Diante do exposto na lei, muitos pesquisadores brasileiros, dentre eles Fernandes $(1999,2003)$ e Quadros $(1997,2003)$, vêm se dedicando à temática do letramento do surdo situada no âmbito da educação bilíngue e bicultural, de maneira a respeitar as culturas surda e ouvinte, e a assegurar que a Língua Brasileira de Sinais seja reconhecida como primeira língua, e a língua portuguesa, na modalidade escrita, como segunda língua.

Essa discussão traz em seu interior uma outra particularmente relevante nos debates sobre bilinguismo, isto é, os enfrentamentos entre línguas majoritárias e minoritárias. De acordo com Fernandes e Moreira (2009),

[...] os surdos podem ser considerados bilíngues ao dominarem duas línguas legitimamente brasileiras, 
${ }^{1}$ FERNANDES, S. É possível ser surdo em português? Língua de sinais e escrita: em busca de uma aproximação. In: SKLIAR, C. (Org.) Atualidades na educação bilíngüe para surdos. Porto Alegre: Mediação, 1999. v. 2, p. 59-81.

${ }^{2}$ Para o propósito desta reflexão, consideraremos o surdo não oralizado. posto que ambas expressam valores, crenças e modos de percepção da realidade de pessoas que compartilham elementos culturais nacionais. Ocorre que uma das línguas - o português - é a língua oficial e majoritária - enquanto que a outra - a Libras - é uma língua minoritária, que não goza de prestígio social e é utilizada por um grupo restrito de pessoas. (p. 226).

Chamamos a atenção, no entanto, para um outro aspecto da problemática envolvida nesse tipo particular de bilinguismo proposto para a educação do surdo. Referimonos à relação entre oralidade e escrita, na medida em que, como afirma Fernandes (2006b),

[...] a língua portuguesa para os surdos constitui um conjunto de signos visuais materializados na escrita: para os surdos, aprender a escrita significa aprender a língua portuguesa. Escrita e língua fundem-se em um único conhecimento vivenciado por meio da leitura. (p. 137 - grifo nosso).

É ainda a mesma autora que lança, à guisa de título de um de seus trabalhos, uma pergunta instigante: É possível ser surdo em português? ${ }^{1}$

Essa questão, além das implicações políticas já mencionadas, merece ser tratada também do ponto de vista da aquisição de uma língua exclusivamente a partir de sua escrita, sugerido na pergunta lançada por Fernandes, assim como no termo bilinguismo, uma vez que, no caso em discussão, a segunda língua do surdo é o português escrito.

Propomo-nos, então, focar esse aspecto da questão, mais precisamente para o que venha a ser a natureza peculiar da linguagem, condição para que se possa refletir sobre as possibilidades de o surdo ${ }^{2}$ ter acesso a uma língua oral de escrita alfabética unicamente através da sua materialidade gráfica. Nesse sentido, já 
assumimos a posição de que é possível, sim, ser surdo em português. Uma posição que nos parece igualmente sustentada por aqueles que propõem o termo bilinguismo para definir a relação do surdo com a Libras e com o português escrito. ${ }^{3}$

Entretanto, tal posicionamento obriga-nos, antes, a levantar também uma outra indagação: o que se está considerando ser o português para que se possa pensá-lo manifestado na oralidade e na escrita de forma independente, de tal maneira que possamos ser ouvintes ou surdos numa mesma língua?

De nossa parte, vamos assumir ser o "português" uma forma linguística particular, - "um todo organizado que tem a estrutura linguística como um princípio dominante" (HJELMSLEV, 1943, p.7) -, que permite aos seus falantes reconhecerem semelhanças e diferenças linguísticas a partir do seu interior, isto é, do que Saussure chamou de sentimento da língua: "Não nos esqueçamos de que tudo o que existe no sentimento dos sujeitos falantes é real. Nós não devemos nos inquietar com o que conseguiu provocar esse sentimento" (SAUSSURE, 2004, p. 160). Desse ponto de vista, nossa afirmação acima sobre a possibilidade de ser surdo em português advém do sentimento provocado naqueles que leem textos escritos por surdos, inclusive em nós, de estarmos diante da nossa língua. Embora haja, com frequência, estranhamentos nessa leitura, sustentamos a posição de que estes são provocados pelo reconhecimento primeiro de se ter ali a "língua portuguesa". ${ }^{4}$

Assumir como possibilidade a passagem do oral para o escrito e o acesso ao escrito sem passar pelo oral, convoca uma reflexão sobre as especificidades formais da linguagem, especificidades estas que extrapolam as considerações sobre línguas particulares, e que não prescindem de uma volta às discussões que ocuparam a linguística moderna, notadamente do início do século $\mathrm{XX}$, a partir da teorização saussuriana.

A esse respeito afirma, por exemplo, Lyons (1987):
${ }^{3}$ Não será dada ênfase aos fracassos das práticas pedagógicas envolvendo a alfabetização do surdo, embora esses sejam recorrentes e acabem por condicionar as conclusões sobre o que está posto em questão relativamente à possibilidade de "ser surdo em português".

${ }^{4}$ A título de simplificação, neste momento, vamos deixar de fora desta discussão características de natureza sonora, como, por exemplo, o ritmo, que diferenciam línguas como Português e Espanhol. Sob esse aspecto, a primeira é classificada como língua de ritmo acentual e a outra como de ritmo silábico. 
[...] A língua tem a propriedade de passar por uma transferência de meio. Trata-se de uma propriedade importantíssima - à qual se vem prestando pouquíssima atenção nas discussões gerais sobre a natureza da linguagem. (p.24 grifo em itálico nosso).

Benveniste (1995), igualmente, ao recusar o entendimento banal de ser a linguagem um instrumento de comunicação, chama a atenção para a sua natureza particular:

Todos os caracteres da linguagem, a sua natureza imaterial, o seu funcinamento simbólico, a sua organização articulada, o fato de que tem um conteúdo, já são suficientes para tornar suspeita essa assimilação a um instrumento, que tende a dissociar do homem a propriedade da linguagem. (p.285 - grifo nosso).

Será a partir da discussão hjelmsleviana sobre forma e substância que pretendemos tratar do tema que nos ocupa neste trabalho. Poucos autores se dedicaram de forma tão metódica ao desvendamento do que venha a ser a "essência" da linguagem. Acreditamos na necessidade de recuperarmos discussões que foram silenciadas ao longo de muitas décadas, de modo especial no Brasil. Antes, porém, de passarmos para as considerações de Hjelmslev sobre as propriedades formais da linguagem, vamos nos deter brevemente num outro aspecto da questão desse tipo especial de bilinguismo, que são as relações entre oralidade e escrita.

\section{A alfabetização do surdo e do ouvinte: a língua natural e sua escrita}

Dentre as inúmeras dificuldades encontradas por alunos, professores e familiares no processo de inclusão dos surdos, a sua "alfabetização" em português merece destaque, conforme mencionamos anteriormente. 
Se a questão se mostra particularmente desafiadora deve-se ao fato de se supor, no termo alfabetização, a existência de uma relação pontual entre fonemas e grafemas, ou seja, a transcrição gráfica da pauta sonora. Não havendo escuta, de que forma essa relação se estabelece? Não casualmente, alguns autores vêm privilegiando o uso do termo letramento ${ }^{5}$ para marcar uma diferença relativamente a essa ideia. A mudança de termo, entretanto, não é garantia de mudança de perspectiva teórica sobre o lugar secundário atribuído à escrita nesses trabalhos, com desdobramentos importantes sobre concepções e práticas pedagógicas que envolvem a aquisição da escrita por surdos e, é importante não esquecer, por não-surdos igualmente.

Para iniciar uma discussão sobre as concepções de escrita envolvidas nos debates sobre o letramento do surdo, destacamos algumas afirmações feitas por Sueli Fernandes (2006) e Ronice Quadros $(2003)^{6}$, autoras que se têm dedicado seriamente à reflexão sobre o direito de o surdo ter uma educação bilingue no Brasil. Da mesma maneira, têm militado pelo reconhecimento de seus direitos à plena cidadania, através da constituição da subjetividade e identidade surdas.

Afirma Fernandes (2006):

Neste trabalho nos ocupamos da discussão das práticas de letramento que envolvem alunos surdos para os quais a língua de sinais configura-se como língua natural e possibilidade privilegiada de acesso e desenvolvimento da linguagem. (p.6 - grifo nosso).

No início do processo de alfabetização é comum que os professores supervalorizem as propriedades fonéticas da escrita, apresentando-a às crianças como um sistema de transcrição da fala. As crianças não-surdas, que pensam e se comunicam por meio da fala, encontram relativa facilidade em aprender a ler e a escrever essa escrita alfabética, já que estabelecem uma relação quase biunívoca entre o que falam e escrevem e vice-

\author{
${ }^{5} \mathrm{O}$ termo letramento \\ expande a noção de \\ alfabetização para além \\ da aprendizagem da \\ leitura e da escrita no \\ início da escolarização, \\ envolvendo a \\ habilidade social de \\ usar, interpretar, \\ extrair informações \\ de diferentes tipos de \\ textos, cf. Kleiman \\ (1995), Soares (2001), \\ dentre outros. \\ ${ }^{6} \mathrm{O}$ trabalho de iniciação \\ científica de Ana \\ Noronha, Concepções \\ de escrita presentes \\ em teses e dissertações \\ que tratam da aquisição \\ da escrita pelo surdo, \\ em desenvolvimento, \\ confirma a forte \\ presença dessas duas \\ autoras como referencial \\ teórico nos trabalhos \\ brasileiros que tratam \\ da questão, justificando \\ nossa escolha.
}


versa. Apenas mais tarde é que percebem o caráter simbólico da escrita e passam a compreender as relações arbitrárias que constituem sua estrutura e funcionamento. (p. 6 - grifo nosso).

Discutindo o contexto escolar do aluno surdo, Quadros (2003) faz as seguintes afirmações:

Um dos problemas que deve ser reconhecido é que a escrita alfabética da língua portuguesa no Brasil não serve para representar significação com conceitos elaborados na língua de sinais brasileira, uma língua visual espacial. Um grafema, uma sílaba, uma palavra escrita no português não apresentam nenhuma analogia com um fonema, uma sílaba e uma palavra na língua de sinais brasileira, mas sim com o português falado. (p. 100).

A escrita da língua de sinais capta as relações que a criança estabelece com a língua de sinais. Se as crianças tivessem acesso a essa forma escrita para construir suas hipóteses a respeito da escrita, a alfabetização seria uma consequência do processo. (p. 101).

Gostaríamos de dar destaque à presença de duas ideias centrais que comparecem nos textos acima, não casualmente voltados para o tratamento de práticas pedagógicas: a) a ideia de naturalidade atribuída à língua oral, neste caso, o português, e visual-espacial, no caso da Libras; b) a suposição de que a relação entre a língua natural e a escrita é da ordem da representação.

Ao assumir esse ponto de vista temos dois desdobramentos facilmente recuperados nos textos acima:

a) No caso do português, o acesso ao oral aparece como uma garantia de acesso ao escrito. Como Fernandes coloca em seu texto: a partir da constatação da dificuldade do surdo, se passa ao argumento da facilidade ou "relativa facilidade" da criança ouvinte ter acesso à escrita. Porém, o testemunho das muitas 
décadas de fracasso escolar na alfabetização da criança não-surda silencia este argumento.

b) O mesmo ocorre com a suposição de que, havendo uma escrita para a língua de sinais, a aquisição da escrita pelo surdo seria uma "consequência [natural?] do processo". Tal pensamento, mais uma vez em contraste com o que ocorre com o ouvinte, sugere que a aquisição da escrita pelo surdo seria mais fácil se houvesse uma escrita para a Libras.

Ao se conceber a escrita de uma ou outra língua como representação da linguagem primeira e natural, seja esta o português ou a Libras, como supor a possibilidade de bilinguismo para o surdo a não ser através de sua oralização? Como apagar a ideia da deficiência - no sentido de falta de algo - quando o fracasso é possível de ocorrer, seja para o surdo ou para o ouvinte?

De Lemos, no texto Sobre o ensinar e o aprender no processo de aquisição de linguagem (1992), chama a atenção para um aspecto estreitamente ligado ao que vimos discutindo. Afirma a autora:

O atributo de 'naturalidade' é parte do conjunto de pressupostos de teorias de aquisição de linguagem desde os primeiros momentos da constituição dessa área como área de pesquisa científica. Pode-se mesmo dizer que sua força enquanto pressuposto, advém de sua consonância com o que nos diz nossa intuição e o senso comum. [...] Colocando esse conjunto de fatos em relação com uma outra experiência comum - a de que os animais não falam -, fica fácil transformá-lo em argumento para um salto decisivo: qualificar essa 'naturalidade' como biológica. Com esse salto, deixam-se para trás, ou de fora, as condições sócio-históricas a que remete obrigatoriamente a referência a instituições como família, escola - sua constituição como espaços sociais respectivamente privado e público - e a própria linguagem. (p.150 - grifo nosso). 


\footnotetext{
${ }^{7}$ Érika Costa, em trabalho inédito, reúne uma extensa lista de referências no campo da fonoaudiologia e da psicologia da educação que assumem a noção de consciência fonológica como requisito para a alfabetização, e conclui ser o fracasso uma questão de deficiência dessa habilidade no aluno que requer treinamento específico.
}

Diante do argumento da "naturalidade" assim construído, surgem com força propostas pedagógicas focadas na discriminação fônica, isto é, na decodificação (cf. CAPOVILLA e CAPOVILLA, 1997, 1998, 2003, 2004, dentre outros). Em entrevista disponibilizada na Rede Psi, o neuropsicólogo Fernando C. Capovilla (2006) afirma:

[Decodificar] é converter os grafemas emfonemas. Aprender a pronunciar a palavra em presença da escrita. Quando pensamos em palavras usamos nossa voz interna. Quando lemos em voz baixa escutamos nossa voz. Isto é o processo fônico: a invocação da fala interna em presença do texto. O método ideovisual desestimula esta fala interna. Ele tenta estimular a leitura visual direta, portanto, a memorização. Só que não é possível memorizar ideograficamente todas essas palavras. A forma correta é aprender a decodificar. Quando fazemos isso, naturalmente se consegue produzir a fala e entender o que se está lendo. (p. 4 - grifo nosso).

A constatação do fracasso do método conduz as análises, muito facilmente, para a assunção de haver um defeito no organismo que não foi capaz de, naturalmente, fazer uso da percepção para decodificar. Isso explica a consideração dos problemas de alfabetização da criança ouvinte, a partir da abordagem clínico-terapêutica, a mesma que se busca afastar no caso do surdo. Termos como consciência fonológica, treinamento de discriminação fônica, dislexia, dentre tantos outros que se multiplicam recentemente na literatura que trata de problemas na alfabetização, sobretudo nos campos da fonoaudiologia, da psicologia da educação e da neuropsicologia, dão à análise de De Lemos uma força excepcional nos dias de hoje. ${ }^{7}$

Embora muitos aspectos dessa reflexão devam ser deixados de lado em função dos limites deste trabalho, parece-nos oportuno avançar, tendo em vista a discussão que pretendemos fazer sobre a natureza peculiar da 
linguagem, condição para que haja algum sentido em se propor o bilinguismo do surdo nos moldes em que este se apresenta para os autores em estudo, isto é, sustentado na possibilidade de se chegar ao português unicamente via escrita - possibilidade remota se considerarmos os pressupostos teóricos defendidos por Capovilla (2006). ${ }^{8}$

Fernandes vem discutindo uma proposta que busca estabelecer uma relação entre a escrita chinesa e a escrita do português pelo surdo: "Para os surdos, reconhecer as palavras do português em um texto funcionaria como identificar ideogramas chineses, atribuindo sentidos à palavra como um todo para chegar ao significado". (FERNANDES, 2006b, p. 137).

Embora esse enfoque desloque a questão da relação pontual fonema/grafema no tratamento da escrita do português, parece-nos que ainda não são enfrentados dois pontos: a ilusão de que a palavra enquanto unidade linguística possa ser apreendida isoladamente, e o lugar secundário reservado à escrita. Notadamente, ficam por explicar as questões do acesso do sujeito ao funcionamento simbólico da linguagem, que não se dá a perceber pela via direta dos sentidos, sejam estes quais forem. A esse respeito, vale retomar a máxima saussuriana de que "a língua é uma forma e não uma substância” (SAUSSURE, 2006, p. 141). Esse é, certamente, o grande desafio colocado para as discussões que envolvem as práticas pedagógicas e que supõem uma relação de ensino-aprendizagem no campo da linguagem.

\section{A escrita como representação}

A questão da anterioridade de uma modalidade de linguagem, concebida como "natural", sobre outra, embora nem sempre posta em questão, foi tema de reflexão para dois importantes autores: Jacques Derrida - notadamente em Gramatologia ${ }^{9}$, obra em que buscou desconstruir a tradição lógico-positivista ocidental, por ele classificada de logocêntrica e fonocêntrica, - e Louis Hjelmslev lingüista dinamarquês fundador da Glossemática, junto
${ }^{8}$ Não ignoramos a extensa produção teórica do autor a propósito da Libras e do surdo. Defendemos no presente trabalho que, tendo em vista a relação estabelecida pelo autor entre uma língua oral e sua escrita alfabética, a oralização é condição para o acesso à escrita, o que impossibilita o bilingüismo do surdo nos moldes aqui referidos.

${ }^{9}$ A presença das considerações de Derrida na reflexão sobre a aquisição da escrita surge de forma original na tese de Sonia Borges Vieira da Mota em 1995, posteriormente publicada sob o nome Sonia Borges em 2006. 
com H. J. Uldall, e do Círculo Linguístico de Copenhagen, juntamente com Viggo Brødal.

Nesta seção vamos dar destaque a alguns pontos da complexa obra de Derrida. Reservamos para a próxima uma discussão preliminar sobre as ideias de Hjelmslev relativamente aos conceitos de forma e substância, conceitos esses que desafiam a nossa compreensão sobre a questão do "acesso" ao linguístico.

Em Gramatologia (1973), Derrida afirma que, na tradição ocidental, a relação entre oralidade e escrita é tratada como sendo da ordem da representação da primeira pela segunda. Nessa relação, fica estabelecida uma hierarquia que coloca a linguagem oral numa posição privilegiada por ser o significante primeiro, mais próximo do pensamento. À escrita é atribuído um valor secundário, com uma "função estrita e derivada" (p.61).

Com a sua reflexão, tecida a partir do pensamento de Freud e de Saussure, mais do que tratar de uma questão especificamente linguística, Derrida visa a romper com a tradição lógico-positivista ocidental, por ele classificada de logocêntrica e fonocêntrica, que "comanda toda a nossa cultura e toda a nossa ciência” (DERRIDA, 1973, p. 37).

Essa tradição baseia-se na filosofia do ser como presença. $O$ privilégio atribuído à voz baseia-se na suposição de que esta esteja mais próxima do pensamento. Como consequência, a palavra sonora é considerada o mais ideal dos signos. Qualquer outro significante seria secundário, uma vez que, primeiramente, remeteria à voz, caso em que se situa a escrita - "signo de signo".

Em seu projeto de desconstrução da tradição filosófica ocidental, o autor enfatiza que o privilégio concedido ao som deve-se, sobretudo, ao efeito que o ouvir-se falar provoca naquele que fala. A ilusão criada é a de que o sentido teria aí a sua origem, justificando-se, dessa maneira, a prerrogativa concedida à consciência.

Saussure, no capítulo VI (Representação da Língua pela Escrita) da Introdução do Curso, clama pela restauração de uma relação natural entre fala e escrita, 
de tal forma que os efeitos danosos da segunda sobre a primeira sejam afastados, e sustenta que "língua e escrita são dois sistemas distintos de signo; a única razão de ser do segundo é representar o primeiro (...)". (SAUSSURE, 2006, p.34).

No entanto, Derrida afirma que é preciso opor Saussure a si mesmo, sobretudo a partir da teoria do valor, que aponta para o reconhecimento de que a letra e o fonema têm "valor puramente negativo e diferencial” (SAUSSURE, 2006, p.138), não possuem uma essência. Sendo assim, o que vincula um ao outro não reside na positividade de suas propriedades, já que elas inexistem. Consequentemente, não é possível representá-los com relação a si próprios, muito menos representar um pelo outro.

Ainda de acordo com Derrida (1973), a tese do arbitrário do signo em Saussure constitui-se num obstáculo para a distinção radical entre signo oral e signo gráfico. O estatuto do signo em Saussure é linguístico, isto é, ele não representa ideia ou coisa - "o próprio do signo é não ser imagem" (p.55). Essa tese rege as relações entre significante e significado e também entre fonema e grafema. Declara ele:

[...] Mesmo na escritura dita fonética, o significante 'gráfico' remete ao fonema através de uma rede com várias dimensões que o liga, como todo significante, a outros significantes escritos e orais, no interior de um sistema 'total', ou seja, aberto a todas as cargas de sentidos possíveis. É da possibilidade deste sistema total que é preciso partir (p.55).

Derrida defende que Saussure, na verdade, estabelece uma ruptura com a tradição filosófica, ressignificando a noção de signo, a qual rompe com a teoria do ser para, na teoria do valor, se constituir signo que representa para outro signo. $O$ temido fascínio provocado pela escrita, apontado reiterada vezes na 
filosofia ocidental, explica-se na medida em que o signo gráfico desfaz o liame pretensamente natural entre significado e significante.

$\mathrm{O}$ autor segue afirmando que esse efeito, a que ele chama de "violência da escritura", revela uma violência originária, "porque a linguagem é primeiramente [...] escrita. A 'usurpação' começou desde sempre” (p.45). A escrita vem evidenciar o movimento de significação que não se interrompe, e desfazer a ideia do significado original, transcendental, de uma linguagem inocente que limitaria o jogo significante.

Embora no caso da Libras não se trate de um "ouvir-se", ainda assim, a ideia de a origem do sentido estar naquele que enuncia, reafirma o lugar privilegiado da consciência na concepção de linguagem assumida e a condição secundária atribuída à escrita, ainda que se trate de uma escrita própria da língua de sinais. Dentre os desdobramentos dessa suposição nas práticas pedagógicas, como já apontamos anteriormente, sobressai a ilusão da garantia do acesso à "representação" da língua primeira, garantia essa que vem sendo sistematicamente negada pelos muitos fracassos na alfabetização.

Derrida (1973) cita Uldall, da Escola de Copenhague, que, a respeito das colocações de Saussure sobre o valor secundário da escrita, lamenta que "a substância da tinta não tenha merecido, da parte dos linguistas, a atenção que dedicaram à substância do ar" (Uldall, H.J. apud Derrida, 1973, p.72 - grifo nosso). Também dá destaque ao fato de a referida Escola liberar um campo de pesquisas inéditas e fecundas no que se refere à expressão gráfica da estrutura do texto. Afirma o autor que "a atenção torna-se disponível não só para a pureza de uma forma desligada de qualquer liame 'natural' a uma substância, mas também para tudo o que, na estratificação da linguagem, depende da substância de expressão gráfica". (DERRIDA, 1973, p. 72 - grifo nosso). 


\section{Forma e substância em Hjelmslev ${ }^{10}$}

A escrita do português pelo sujeito surdo envolve ainda uma série de considerações teóricas particulares, dentre elas aquela que Hjelmslev (1943) assinalava faltar nos estudos linguísticos, isto é, uma análise da escritura sem considerar o som. Essa afirmação, feita em 1943, permanece válida para os dias atuais e nos deteremos a explorar um pouco as ideias desse autor nesta seção.

Se o surdo não pode dispor da oralidade, parece legítimo supor que será com a matéria gráfica que ele terá que se haver de maneira privilegiada ${ }^{11}$ para tornála linguística. Mas isso não significa, evidentemente, uma simples memorização da grafia de cada palavra.

Para os objetivos deste trabalho, será feita uma discussão sobre os conceitos de forma e substância, conforme propôs Hjelmslev, notadamente em seus Prolegômenos a uma teoria da linguagem. ${ }^{12}$ Neste momento será deixada de lado a análise original do autor, que separa forma e substância nos planos da expressão e do conteúdo. Partiremos tão somente das ideias mais gerais implicadas no desenvolvimento da proposição saussuriana de que língua é forma e não substância, notadamente nos conceitos de texto (processo, paradigmática) e língua (sistema, sintagmática). A ênfase será dada à relação contraída entre substância e forma da expressão, sem dar maior destaque ao que esta reflexão exclui em termos do plano do conteúdo.

Ao argumentar sobre as consequências teóricas advindas da separação saussuriana entre forma e substância, Hjelmslev (1943) faz inúmeras referências à linguagem dos surdos e a outros sistemas semiológicos, ampliando sua reflexão para além da suposição de que a linguagem oral é tradução de linguagem "natural".

Assumir que a língua é uma entidade autônoma implica reconhecer ser esta "constituída essencialmente de dependências internas" (HELMSLEV, 1948, p. 32). Como consequência, "fatos" não podem preceder logicamente as relações que os unem. Com isso, conclui o autor, nega-se
${ }^{10}$ Registramos nosso reconhecimento às observações de Lucila Costa, que em sua dissertação de mestrado buscou as idéias deste autor para tratar da escrita de jovens e adultos, notadamente os conceitos de texto e de figura. Algumas das reflexões, ainda embrionárias, presentes nesta parte do trabalho surgiram de nossas muitas conversas.

${ }^{11} \mathrm{O}$ privilégio concedido à matéria gráfica não descarta da relação do surdo com o português oral os movimentos faciais e gestos dos ouvintes. Sobre a substância da expressão, observa Hjelmslev (1943): "a fala é acompanhada pelo gesto e pela mímica, com algumas de suas partes podendo mesmo ser substituídas por estes" (p.111).

${ }^{12}$ A definição dos termos forma e substância se complexifica em trabalhos posteriores. Em A estratificação da linguagem (1954), por exemplo, ocorrem alterações importantes sobre as relações mútuas previstas entre forma e substância. Não vamos aqui nos deter nesse aspecto do problema, reservando-o para discussões futuras. 


\footnotetext{
${ }^{13}$ Mais uma vez seremos obrigados à simplificar os conceitos aqui veiculados. As discussões de Hjelmslev sobre o que caracteriza o texto apontam para a complexidade dessa unidade que repousa na coexistência de sistemas diferentes.
}

a "existência científica de uma substância absoluta, ou de uma realidade independente das relações” (p. 32).

Dessa última afirmação, pode-se deduzir que, na percepção de Hjelmslev, a língua portuguesa, ou qualquer outra, não tem a sua existência atrelada à substância sonora, mas às relações que são manifestadas pela substância selecionada, seja esta sonora, gráfica, gestual ou qualquer outra. Ou seja, "a 'substância' não pode em si mesma definir uma língua” (HJELMSLEV, 1943, p. 110). Conclui-se, ainda, que a escrita não é derivada da oralidade, uma vez que esta perde seu lugar de substância primeira/ natural. Conforme mencionamos anteriormente, esse último postulado levou Derrida a exaltar a novidade da Escola de Copenhagem. Hjelmslev (1943a) chega mesmo a afirmar, em uma nota de rodapé, que "é com justa razão que B. Russell insiste sobre a ausência de qualquer critério para decidir qual é o mais antigo meio de expressão do homem, se a escrita ou a fala" (p. 111).

O que condiciona a substância gráfica não é, portanto, a substância sonora, mas a forma manifestada por esta última, que, no caso em discussão, refere-se à "língua portuguesa" - ou, nos termos de Hjelmslev, ao esquema linguístico que a caracteriza. As relações é que constituem a essência da língua e estas (as relações) se manifestam no jogo da substância selecionada, e não podem ser percebidas sensorialmente. Nesse sentido, o caráter simbólico da escrita não se sucede a uma apreensão pontual entre fonema e grafema, como afirma Fernandes (2006). Ao contrário, ele é a condição para que as relações entre as pautas sonora e escrita possam ser imaginariamente isoladas numa "relação biunívoca", como farão os já alfabetizados.

As afirmações anteriores exigem que se explicite outro conceito fundamental proposto pelo autor, isto é, a noção de texto, estritamente vinculado à separação forma/substância. Essa noção exerce um papel fundamental sobre a reflexão hjelmsleviana. O texto ${ }^{13}$ se define como processo ou sintagmática, que contrai uma 
função semiótica mútua com a língua, definida como sistema ou paradigmática.

Portanto, se se trata, de uma "manifestação substancial" da forma linguística, o texto escrito não se restringe a uma "massa de letras" em relação biunívoca com uma "massa sons". Como afirma Hjelmslev (1943), "a mesma forma linguística pode [...] manifestar-se por escrito [...] Trata-se, aqui, de uma 'substância' gráfica que se dirige apenas ao olho e que não precisa ser transportada em 'substância' sonora a fim de ser percebida ou compreendida”. (p. 111).

Ou seja, o texto - oral ou escrito - não se encontra ao alcance direto da percepção, uma vez que nele não se inscreve uma coleção de objetos isolados/atômicos - sejam esses de que matéria forem - mas uma teia de relações e dependências que só existem em função do todo de que participam. Sem o texto não se pode pensar em relações. A discussão que Hjelmslev faz do termo função por ele adotado ajuda a compreender melhor do que se trata:

Poderemos dizer que uma grandeza no interior de um texto ou de um sistema tem determinadas funções e, com isso, aproximamo-nos do emprego lógico-matemático desse termo [função], com ele exprimindo: primeiramente, que a grandeza considerada mantém dependência ou relações com outras grandezas, de modo que certas grandezas pressupõem outras e, segundo, que pondo em causa o sentido etimológico do termo [função], esta grandeza funciona de uma determinada maneira, representa um papel particular, ocupa um 'lugar' preciso na cadeia. (HJELMSLEV, 1943, p. 40).

Do ponto de vista das ideias defendidas por Hjelmslev, a resposta à pergunta lançada por Fernandes é certamente positiva, embora fique por se considerar em trabalhos futuros uma série de outras questões fundamentais que dizem respeito aos conceitos teóricos 
aqui mencionados, assim como à confrontação destes com a análise da escrita e da leitura do surdo.

No momento, entretanto, vamos dar destaque a uma questão em particular: de que maneira a matéria gráfica presente no texto se transforma em substância linguística, isto é, em manifestação substancial de uma forma para aquele que lê? Essa é uma mudança que se opera, não no objeto empírico texto escrito, mas na relação que o sujeito (surdo ou ouvinte) estabelece com ele, através de um deslocamento daquilo que seus sentidos captam. Isto é, se antes o texto era simplesmente percebido em sua imagem gráfica, ele, sendo o mesmo e não o sendo mais, pode ser lido, para além da decodificação, "no interior de um sistema 'total', ou seja, aberto a todas as cargas de sentidos possíveis" como mencionou Derrida (1973, p. 55).

A noção de captura simbólica proposta por De Lemos (2002), no campo da Aquisição de Linguagem, toca nesse ponto da nossa reflexão, pois vem, precisamente, inverter a direção da relação sujeito-objeto no que se refere à linguagem:

[...] Considerada em seu [da linguagem] funcionamento simbólico, poder-se-ia inverter a relação sujeito-objeto, conceber a criança como capturada por um funcionamento linguísticodiscursivo que não só a significa como lhe permite significar outra coisa, para além do que a significou. (p.60).

Acreditamos que, quando o que está em foco é a aquisição de linguagem oral ou escrita, considerações como essa não podem ser ignoradas, pois apontam para a necessidade de uma teoria para pensar o sujeito e sua relação com a língua, reconhecida por sua "autonomia e alteridade radical" (idem), afetando, em consequência, a própria teoria sobre a linguagem.

As questões de que se ocupam muitos autores, relativamente aos processos de identificação e subjetivação do surdo, são, portanto, essenciais. No entanto, não 
prescindem de uma reflexão que enfrente as questões que se voltam para a natureza particular da linguagem, a fim de que a referência ao bilinguismo não caia nas armadilhas do biológico. Esse é um risco sempre presente quando se trata de por em discussão a relação sujeito/linguagem. 


\section{Referências}

BENVENISTE, Émile. Da subjetividade na linguagem [1958]. In: . Problemas de Lingüística Geral I. Campinas, SP:

Pontes, 1995.

BRASIL, Lei no 10.436 de 24 de abril de 2002. Disponível em: http://www.mec.gov.br/legis/pdf/lei10436.pdf.

CAPOVILLA, Fernando. C. Alfabetização no Brasil - Uma metodologia ultrapassada, 2006. Disponível em http://www. redepsi.com.br/portal

CAPOVILLA, Alessandra G. S., \& CAPOVILLA, F. C. O desenvolvimento da consciência fonológica durante a alfabetização. Temas sobre Desenvolvimento, n.6, v.36, p. 1521, 1997.

CAPOVILLA, Alessandra G. S., \& CAPOVILLA, F. C. Problemas de leitura e escrita: como identificar, prevenir e remediar numa abordagem fônica. 2a. ed. São Paulo, SP: Memnon, Edipusp, Fapesp, 2003.

CAPOVILLA, Alessandra G. S., \& CAPOVILLA, F. C. Alfabetização: método fônico. 3a. ed. São Paulo, SP: Memnon, Fapesp, CNPq, 2004.

CAPOVILLA, Alessandra G. S., \& CAPOVILLA, F. C. Alfabetização fônica: construindo competência de leitura e escrita. 2a. ed. São Paulo, SP: Casa do Psicólogo, 2005.

DE LEMOS, Cláudia T. G. Sobre o ensinar e o aprender no processo de aquisição de linguagem. Caderno de Estudos Lingüísticos, Campinas, IEL/Unicamp, n. 22, p.149-52, jan./ jun. 1992.

DE LEMOS, Cláudia T. G. Das Vicissitudes da fala da criança e de sua investigação. Cadernos de Estudos Lingüísticos, Campinas, IEL/Unicamp, n.42, p. 41-70, 2002. 
DERRIDA, Jacques. Gramatologia. São Paulo: Perspectiva, 1973

FERNANDES, Sueli F. Educação bilíngüe para surdos: Identidades, diferenças, contradições e mistérios. Curitiba, 2003, Tese (Doutorado em Letras). Universidade Federal do Paraná.

FERNANDES, Sueli F. Práticas de letramento na educação bilíngüe para surdos. Curitiba : SEED, 2006a.

FERNANDES, Sueli. Letramentos na educação bilíngüe para surdos: caminhos para a prática pedagógica. In: BERBERIAN, A. P.; MORI-DE-ANGELIS, C.; MASSI, G. (Org.) Letramento: referências em saúde e educação. São Paulo: Plexus, 2006b. p.117-144.

FERNANDES, Sueli e MOREIRA, Laura C. Desdobramentos politico-pedagógicos do bilinguismo para surdos: reflexões e encaminhamentos. Revista "Educação Especial" v. 22, n. 34, p. 225-236, maio/ago. 2009, Santa Maria. Disponível em: http:// www.ufsm.br/revistaeducacaoespecial

\author{
${ }^{14}$ Quando necessário, foi \\ utilizada a convenção \\ [ano] indicando o ano \\ da publicação original, \\ seguido da data da obra \\ consultada.
}

HJELMSLEV, Louis. Prolegômenos a uma teoria da linguagem. São Paulo: Perspectiva, [1943] $]^{14} 2006$.

HJELMSLEV, Louis. Linguística estrutural [1948]. In:

Ensaios linguísticos. São Paulo: Perspectiva, 1991.

KARNOPP, L. B. Aquisição do parâmetro configuração de mão dos sinais da Libras: estudo sobre quatro crianças surdas filhas de pais surdos. Dissertação de Mestrado. Instituto de Letras e Artes. PUCRS. Porto Alegre. 1994.

LYONS, John. Língua(gem) e lingüística: uma introdução. Rio de Janeiro: LTC, 1987.

QUADROS, Ronice M. Educação de Surdos - a aquisição da linguagem. Porto Alegre, RS: Artes Médicas, 1997. 
QUADROS, Ronice M. de Situando as diferenças implicadas na educação de surdos: inclusão/exclusão. Ponto de Vista , Florianópolis, n.05, p. 81-111, 2003

SAUSSURE, Ferdinand. Curso de lingüistica geral. São Paulo: Cultrix, [1916] 2006.

SAUSSURE, Ferdinand. Escritos de lingüística geral. São Paulo: Cultrix, 2004. (Organizados e editados por Simon Bouquet e Rudolf Engler)

SKLIAR, Carlos. (Org.). A surdez: um olhar sobre as diferenças. Porto Alegre: Mediação, 1998.

254 Leitura - Maceió, N.47, P. 233-254, JAN./JUn. 2011 